\title{
ANALISIS KARAKTERISTIK DAN KEBUTUHAN PARKIR TERMINAL KARGO DI KOTA DENPASAR
}

Nyoman Gery Arishandi ${ }^{1}$, P. Alit Suthanaya ${ }^{2}$, D.M. Priyantha Wedagama. ${ }^{2}$

\begin{abstract}
Abstrak: Terminal Kargo dengan jumlah petak parkir sebanyak 70 unit merupakan kontrol penyelenggaraan angkutan barang yang melintas di pusat kota dan sebagai tempat bongkar muat kendaraan barang yang tidak memiliki gudang. Namun demikian, aktivitas bongkar muat barang masih banyak dilakukan di ruang milik jalan yang menyebabkan kemacetan lalu lintas. Hal ini memicu Pemerintah Kota Denpasar untuk mengembangkan Terminal Kargo Kota Denpasar sehingga dapat memenuhi permintaan parkir dan aktivitas bongkar muat. Tujuan penelitian ini untuk menganalisis karakteristik parkir dan kebutuhan parkir ke depannya dalam pengembangan Terminal Kargo Kota Denpasar. Metode yang digunakan untuk memperoleh data melalui survai langsung ke lapangan antara lain survai inventarisasi dan survai parkir kordon serta data sekunder yang diperoleh dari instansi terkait.

Hasil analisis menunjukkan volume kendaraan parkir adalah 44,5 kendaraan/jam, kapasitas parkir adalah 36 kendaraan/jam dengan penyediaan parkir sebanyak 372 kendaraan dengan Indeks Parkir 4 yang menunjukkan telah terjadi permasalahan parkir di Terminal Kargo Denpasar. Besarnya kebutuhan parkir untuk pengembangan Terminal Kargo berdasarkan karakteristik parkir adalah 101 petak parkir.
\end{abstract}

Kata kunci: Angkutan barang, karakteristik parkir, kebutuhan parkir.

\section{CHARACTERISTIC AND PARKING NEEDS ANALYSIS OF TERMINAL KARGO IN DENPASAR CITY}

\begin{abstract}
Cargo Terminal which has 70 units space is holding control of freight passing through the city center and as a place of loading and unloading of goods vehicles which do not have a warehouse. However, the activity of loading and unloading of goods is still widely practiced in the right of way which causes traffic jams. This triggers the Denpasar government to develop Terminal Kargo Denpasar so as to supply the demand for parking and loading and unloading activities. The purpose of this study was to analyze the characteristics of the parking and future parking needs in developing Terminal Kargo Denpasar. The method used to obtain data through direct surveys such as inventory survey and survey cordon parking and secondary data obtained from the relevant agencies.

The analysis shows the volume of parking of vehicles is 44,5 vehicles / hour, parking capacity is 36 vehicles / hour, parking supply as much as 372 vehicles and 4 for Parking Index that indicates there has been a problem of parking in the Terminal Cargo Denpasar. It is show Terminal Kargo Denpasar has been unable to supply activity goods vehicles. The amount of the parking requirements for development of Terminal Kargo based on parking characteristic analysis are 101 spaces.
\end{abstract}

Keywords: Transport of goods, parking characteristics, parking needs.

\footnotetext{
${ }^{1}$ Mahasiswa Program Magister Teknik Sipil, Fakultas Teknik, Universitas Udayana, Denpasar

${ }^{2}$ Staf Pengajar Program Magister Teknik Sipil, Fakultas Teknik, Universitas Udayana, Denpasar
} 


\section{PENDAHULUAN}

Fungsi utama terminal adalah untuk menyediakan prasarana masuk dan keluar dari obyek-obyek yang akan digerakkan, penumpang atau barang, menuju dan dari sistem (Morlok, 1985).

Terminal Kargo dengan daya tampung kendaraan besar sebanyak 50 unit ini, adalah sebagai kontrol penyelenggaraan angkutan barang yang melintas di pusat kota dan sebagai tempat bongkar muat kendaraan barang yang tidak memiliki gudang. Terkait dengan kendaraan barang yang tidak melakukan bongkar muat di Terminal tersebut, diijinkan bongkar muat pada gudanggudangnya sendiri, selama tidak melakukan aktivitas di badan jalan.

Parkir di badan jalan oleh angkutan barang terjadi akibat minimnya lahan bongkar muat yang tersedia di Terminal Kargo yaitu terbatas hanya untuk 50 unit kendaraan.

Berdasarkan hasil penelitian terdahulu dan informasi mengenai permasalahan angkutan barang di Kota Denpasar dari berbagai sumber, Pemerintah Kota Denpasar sedang menyusun rencana pengembangan Terminal Kargo yang berlokasi di sebelah Barat Terminal Kargo Denpasar yang ada saat ini. Untuk kondisi saat ini, belum diketahui karakteristik parkir dan kebutuhan pengembangan di Terminal Kargo Denpasar. Maka dari itu perlu dilakukan analisis karakteristik parkir dan kebutuhan pengembangan terminal ke depannya demi memenuhi permintaan aktivitas bongkar muat di terminal. Penelitian ini bertujuan:

1. Untuk menganalisis karakteristik parkir di Terminal Kargo Denpasar.

2. Untuk menganalisis kebutuhan pengembangan Terminal Kargo Denpasar berdasarkan karakteristik parkir yang ada.

\section{KARAKTERISTIK PARKIR}

Informasi mengenai karakteristik parkir sangatlah diperlukan pada saat merencanakan suatu lahan parkir. Beberapa parameter karakteristik parkir yang harus diketahui adalah:

\section{Volume Parkir}

Volume parkir adalah jumlah kendaraan yang termasuk dalam beban parkir yaitu jumlah kendaraan per periode waktu tertentu, biasanya per hari. Rumus yang digunakan untuk menghitung volume adalah:

Volume $=$ Nin $+X($ kendaraan $)$

Keterangan:

Nin : Jumlah kendaraan yang masuk (kendaraan)

$\mathrm{X}$ : Kendaraan yang sudah ada sebelum waktu survai (kendaraan)

\section{Akumulasi Parkir}

Akumulasi parkir adalah jumlah keseluruhan kendaraan yang parkir di suatu tempat pada waktu tertentu (Hobbs, 1979).

\section{Lama Waktu Parkir (Durasi)}

Lama waktu parkir atau durasi adalah lama waktu yang dihabiskan oleh pemarkir pada ruang parkir. Lamanya parkir dinyatakan dalam jam.

Rumus yang digunakan untuk menghitung rata-rata lamanya parkir adalah (Oppenlander, 1976):

$$
\mathrm{D}=\frac{\sum(\mathrm{Nx}) \mathrm{x}(\mathrm{X}) \mathrm{x}(\mathrm{I})}{\mathrm{Nt}}
$$

Keterangan:

$$
\begin{array}{lll}
\mathrm{D}: & \begin{array}{l}
\text { Rata-rata lama parkir atau durasi } \\
\text { (jam/kendaraan) }
\end{array} \\
\mathrm{N}(\mathrm{x}): & \begin{array}{l}
\text { Jumlah kendaraan yang parkir selama } \\
\text { interval waktu survai (kendaraan) }
\end{array} \\
\mathrm{X}: & \text { Jumlah dari interval } \\
\mathrm{I}: \text { Interval waktu survai (jam) } \\
\mathrm{Nt}: \text { Jumlah total kendaraan selama waktu } \\
\end{array}
$$

\section{Tingkat Pergantian Parkir (Parking Turn Over)}

Tingkat pergantian parkir (TR) akan menunjukkan tingkat penggunaan ruang parkir yang diperoleh dari pembagian antara jumlah total kendaraan yang parkir dengn jumlah petak parkir yang tersedia selama waktu pengamatan. Rumus yang digunakan untuk menghitung tingkat pergantian parkir adalah (Oppenlander, 1976):

$$
\mathrm{TR}=\frac{\text { Totak Kendaraan }(\text { Kendaraan })}{\text { (Total petak parkir }) \mathrm{x}(\text { Periode Survai })}
$$

TR dalam (Kendaraan/petak/jam).

\section{Kapasitas Parkir}

Rumus yang digunakan untuk menghitung kapasitas parkir (KP) adalah:

$$
\mathrm{KP}=\frac{\text { Total petak parkir }}{\text { Rata }- \text { rata lama parkir }(\mathrm{jam} / \text { kendaraan })}
$$

\section{Penyediaan Parkir}

Penyediaan parkir atau kemampuan penyediaan parkir adalah batas ukuran banyaknya kendaraan yang dapat ditampung selama periode waktu tertentu (selama waktu survai). Rumus yang digunakan untuk menghitung penyediaaan parkir adalah (Oppenlander, 1976)

$$
\text { Ps }=\frac{(\text { Total petak }) \times(\text { Lama Survai }(\text { jam }))}{\text { Rata }- \text { rata lama parkir }} \times F
$$

Keterangan:

$$
\text { F : Insufficiency factor }(0,85-0,90)
$$

\section{Indeks Parkir}

Indeks parkir adalah perbandingan antara akumulasi parkir dengan kapasitas parkir. Rumus 
yang digunakan untuk menghitung nilai indeks adalah:

$$
\mathrm{IP}=\frac{\text { AkumulasiParkir }}{\text { KapasitasParkir }}
$$

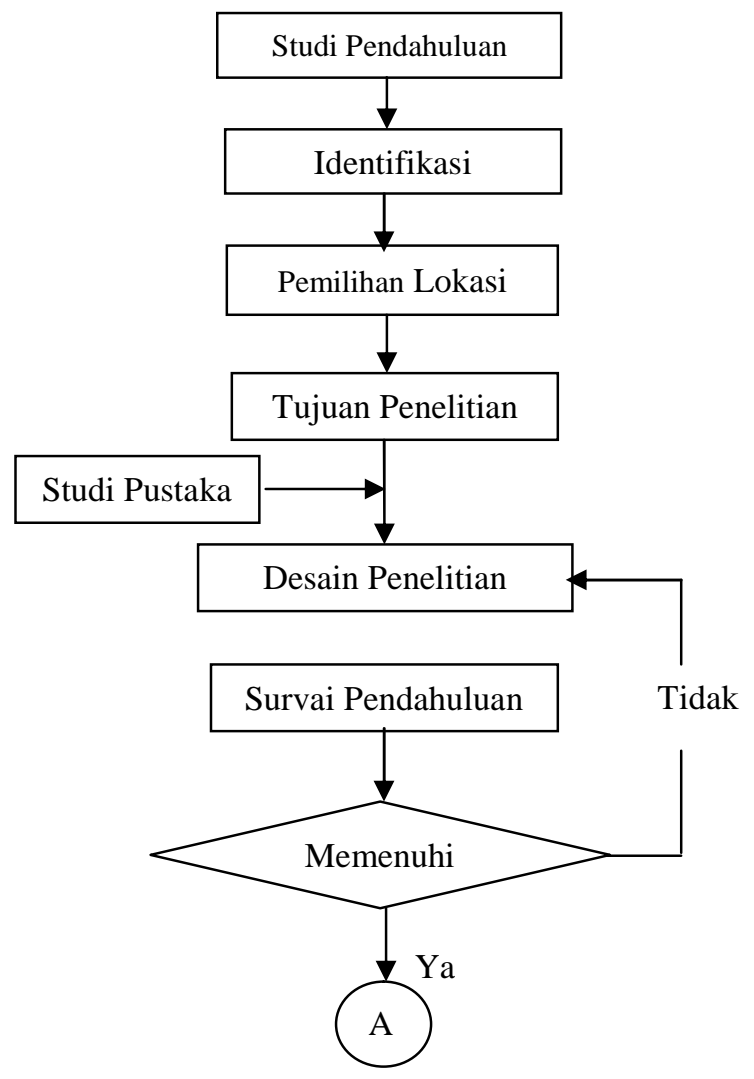

Gambar 1.

Diagram Alir Karkteristik dan Kebutuhan

Parkir Terminal Kargo Denpasar

Jika nilai IP melebihi 1 maka perlu diadakan analisis untuk pengembangan kebutuhan parkir.

\section{METODE}

\section{Data Primer}

Survai data primer yang dilakukan meliputi survai inventarisasi parkir dan survai kordon parkir untuk menganalisis karakteristik parkir Terminal Kargo Denpasar.

\section{Data Sekunder}

Data sekunder merupakan penunjang bagi survai lapangan. Data sekunder didapatkan dari instansi terkait (Dishub dan BPS) seperti: jumlah kendaraan barang yang terdaftar, gambar lokasi Terminal Kargo, data angkutan dan barang yang masuk ke Terminal Kargo serta sistem operasional dan dasar hukum yang mengatur operasional Terminal Kargo dan data penunjang lainnya yang berhubungan dengan angkutan barang di Kota Denpasar.

\section{Rancangan Penelitian}

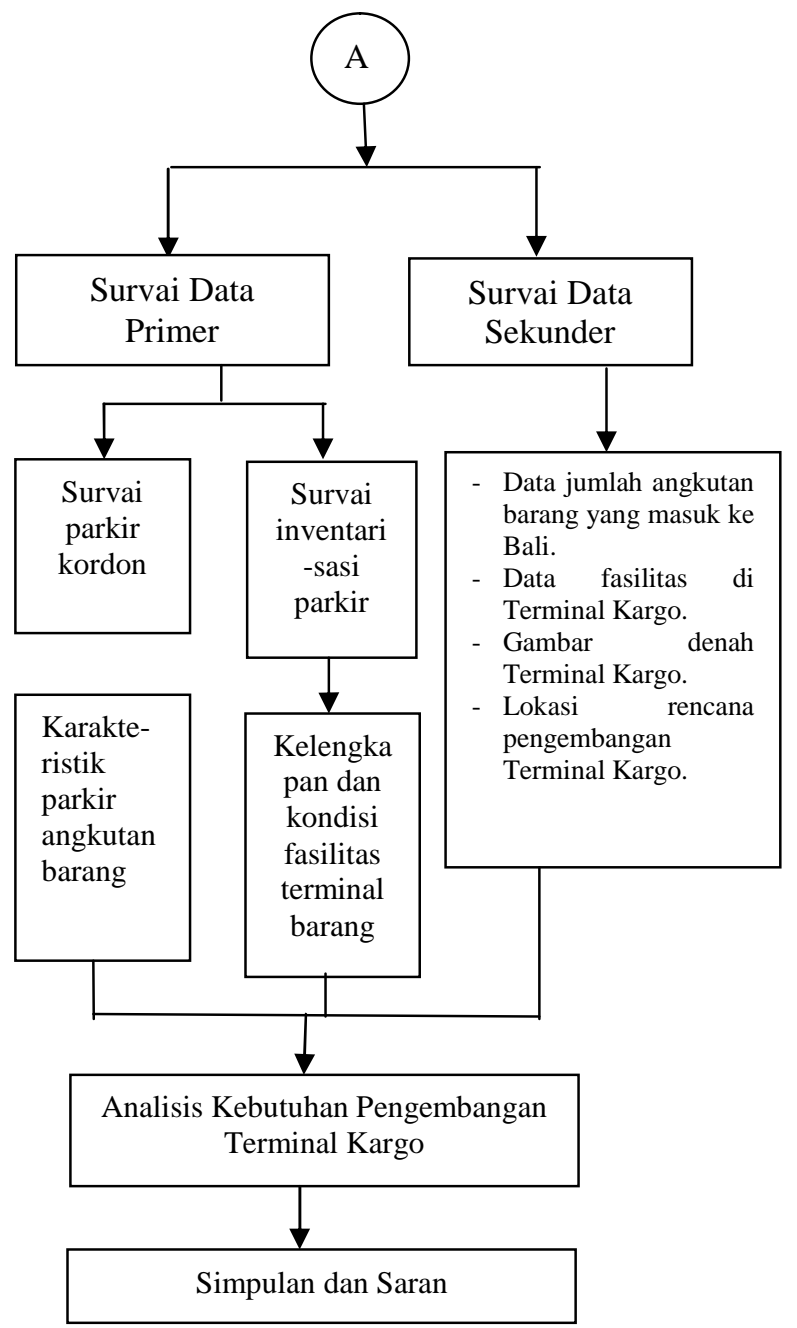

Penelitian dan Waktu Penelitian

Lokasi yang dipilih dalam penelitian ini adalah Terminal Kargo Denpasar yang beralamat di Jalan Galunggung. Penelitian dilaksanakan pada hari Senin, 26 Oktober 2015 pukul $\quad 08.15-20.15$ selama 12 jam.

HASIL DAN PEMBAHASAN

Karakteristik Parkir di Terminal Kargo Denpasar

Sistem parkir yang ada pada Terminal Kargo Denpasar adalah sistem parkir di luar badn jalan (off street parking). Berdasarkan hasil survai, diperoleh jumlah petak parkir kendaraan berat di Terminal Kargo Denpasar yaitu 70 SRP dan sudut petak parkir $90^{\circ}$ (Tabel 1). 


\section{Volume Parkir}

Analisis data hasil survai menunjukkan volume kendaraan yang parkir di lokasi studi selama 12 jam dengan jumlah kendaraan selama survai 534 kendaraan sehingga volume parkir adalah 44,5 kendaraan/jam.

\section{Akumulasi Parkir}

Akumulasi parkir tertinggi di Terminal Kargo terjadi pada pukul 08.15-09.15 yaitu 144 kendaraaan/jam. Berdasarkan hasil survai, dibuat grafik hubungan antara volume dengan waktu yang di survai yang nantinya akan diketahui nilai akumulasi parkir tertinggi (Gambar 2).

\section{Waktu Rata-rata Lama Parkir}

Berdasarkan hasil perhitungan maka diperoleh rata-rata lama parkir kendaaraan di seluruh petak selama 12 jam survai dengan interval 15 menit atau 0,25 jam adalah $1,92 \mathrm{jam} / \mathrm{kendaraan}$

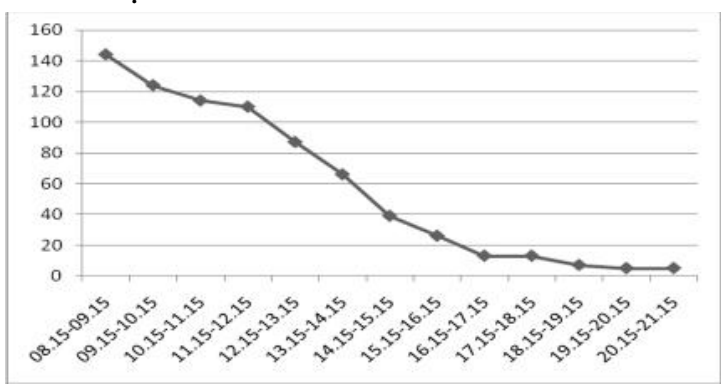

Gambar 2. Grafik Akumulasi ParkirKendaraan Angkutan Barang Terminal Kargo Denpasar

\section{Tingkat Pergantian Parkir}

Berdasarkan hasil analisis dapat diketahui bahwa tingkat pergantian parkir untuk kendaraan barang 0,64 kendaraan/petak/jam yang berarti bahwa setiap jamnya satu petak parkir kendaraan melayani kurang dari 1 buah kendaraan.
$\mathrm{TR}=\frac{\mathrm{Nt}}{(\mathrm{S}) \mathrm{x}(\mathrm{Ts})}=\frac{534}{70 \times 12}=0,64 \mathrm{kend} /$ petak $/ \mathrm{jam}$

\section{Kapasitas Parkir}

Kapasitas parkir berdasarkan hasil analisis adalah 36 Kendaraan/jam.

$\mathrm{KP}=\frac{\mathrm{S}}{\mathrm{D}}=\frac{70}{1,92}=36$ Kendaraan $/ \mathrm{jam}(4)$

\section{Penyediaan Parkir}

Penyediaan parkir (parking supply) atau kemampuan penyediaan parkir berdasarkan hasil analisis adalah:

Ps $=\frac{(\mathrm{S}) \mathrm{x}(\mathrm{Ts})}{\mathrm{D}} \times \mathrm{F}=\frac{70 \times 12}{1,92} \times 0,85=372$ kendaraan

Berdasarkan perhitungan diperoleh bahwa kemampuan penyediaan parkir selama waktu survai adalah 372 kendaraan dengan jumlah kendaraan yang masuk sebanyak 534 kendaraan.

\section{Indeks Parkir}

Berikut hasil analisis indeks parkir Terminal Kargo Denpasar pada jam puncak 08.15 -09.15:

$\mathrm{IP}=\frac{\text { AkumulasiParkir }}{\text { KapasitasParkir }}=\frac{144}{36}=4$

Hasil analisis menunjukkan bahwa indeks parkir tertinggi di Terminal Kargo Denpasar mencapai 4 yang berarti bahwa kondisi parkir pada Terminal Kargo untuk kendaraan barang mempunyai indeks parkir melebihi 1. Hal ini berarti perlu diadakan pengembangan parkir di Terminal Kargo Denpasar sehingga harus dianalisis kebutuhan parkir di Terminal Kargo saat ini.

Tabel 1.

Inventarisasi Fasilitas Parkir Terminal Kargo Denpasar

\begin{tabular}{cccc}
\hline Segmen & Jumlah Petak & Sudut Parkir & Ukuran Petak \\
\hline Stall Parkir A1 & 13 & $90^{0}$ & $3,5 \mathrm{~m} \times 12,3 \mathrm{~m}$ \\
Stall Parkir A2 & 8 & $90^{0}$ & $3,5 \mathrm{~m} \times 12,3 \mathrm{~m}$ \\
Stall Parkir B1 & 10 & $90^{0}$ & $3,5 \mathrm{~m} \times 5 \mathrm{~m}$ \\
Stall Parkir B2 & 9 & $90^{0}$ & $3,5 \mathrm{~m} \times 6 \mathrm{~m}$ \\
Stall Parkir C & 12 & $90^{0}$ & $3,5 \mathrm{~m} \times 12,3 \mathrm{~m}$ \\
Stall Parkir D1 & 4 & $90^{\circ}$ & $3,5 \mathrm{~m} \times 12,3 \mathrm{~m}$ \\
Stall Parkir D2 & 14 & $90^{\circ}$ & $3,5 \mathrm{~m} \times 12,3 \mathrm{~m}$ \\
Jumlah Total & 70 & &
\end{tabular}

Sumber: Hasil Survai,2015 


\section{Analisis Tingkat Kebutuhan Parkir Berdasarkan Akumulasi Kendaraan Angkutan Barang}

Melalui analisis kebutuhan pengembangan parkir (S) dengan menggunakan nilai akumulasi kendaraan tertinggi maka diperoleh hasil sebagai berikut:

$\mathrm{S}=\frac{(\mathrm{NtxD})}{(\mathrm{TsxF})} \frac{534 \times 1,92}{12 \times 0,85}=101$ petak parkir

Jadi dengan jumlah kendaraan barang yang masuk sebesar 534 kendaraan dan rata-rata lama parkir 1,92 jam maka petak parkir yang seharusnya tersedia untuk melayani seluruh angkutan barang adalah 101 petak.

Berdasarkan data inventarisasi, jumlah petak parkir untuk kendaraan besar ukuran 3,4 m x 12,5 m sebanyak 51 petak atau $72,86 \%$ dan petak parkir untuk kendaraan kecil ukuran $3,5 \mathrm{~m}$ x $5 \mathrm{~m}$ berjumlah 10 petak atau $14,28 \%$ serta ukuran $3,5 \mathrm{~m}$ x 6 m sebanyak 9 kendaraan atau $12,86 \%$. Berdasarkan hasil survai inventarisasi parkir dan analisis kebutuhan parkir, maka komposisi kebutuhan pengembangan parkir adalah:

Tabel 2.

Kebutuhan Pengembangan Parkir

\begin{tabular}{lll}
\hline $\begin{array}{l}\text { Petak Parkir } \\
\left(\mathrm{m}^{2}\right)\end{array}$ & $\begin{array}{l}\text { Persentase } \\
\text { Jumlah Petak } \\
\text { Parkir }\end{array}$ & $\begin{array}{l}\text { Rencana } \\
\text { Kebutuhan } \\
\text { Pengembangan } \\
\text { (SRP) }\end{array}$ \\
\hline $3,5 \times 6$ & $12,86 \%$ & 13 \\
$3,5 \times 5$ & $14,28 \%$ & 14 \\
$3,4 \times 12,5$ & $72,86 \%$ & 74 \\
\hline Total & & 101 \\
\hline
\end{tabular}

Sumber: Hasil Analisis, 2015

\section{SIMPULAN DAN SARAN}

\section{Simpulan}

1. Karakteristik parkir Terminal Kargo Denpasar berdasarkan survai 12 jam menghasilkan, inventarisasi petak parkir ukuran $3,5 \mathrm{~m} \mathrm{x} 12,5$ $\mathrm{m}$ sebanyak 51 petak, ukuran $3,5 \mathrm{~m} \times 5 \mathrm{~m}$ sebanyak 10 petak, dan $3,5 \mathrm{~m}$ x $6 \mathrm{~m}$ sebanyak 9 petak parkir. Volume parkir selama survai 12 jam adalah 44,5 kendaraan/jam. Akumulasi parkir tertinggi adalah 144 kendaraan/jam pada jam 08.15-09.15 Rata-rata lamanya parkir adalah $1,92 \mathrm{jam} / \mathrm{kendaraan}$. Tingkat pergantian parkir sebesar 0,64 Kendaraan/petak/jam. Kapasitas parkir sebesar 36 kendaraan/jam. Penyediaan parkir sebanyak 372 kendaraan dengan indeks parkir tertinggi adalah 4.

2. Berdasarkan karakteristik parkir yang ada, kebutuhan parkir di Terminal Kargo Denpasar adalah jumlah petak parkir yang diperlukan saat ini berdasarkan volume kendaraan yang parkir adalah 101 petak. Rencana kebutuhan petak parkir untuk pengembangan Terminal Kargo ke depan adalah sebagai berikut, ukuran $3,5 \mathrm{~m}$ x 6 m sebanyak 13 petak, ukuran $3,5 \mathrm{~m}$ x $5 \mathrm{~m}$ sebanyak 14 petak, dan ukuran $3,4 \mathrm{~m} \times 12,5 \mathrm{~m}$ sebanyak 74 petak.

\section{Saran}

Berdasarkan hasil survai langsung saat survai inventarisasi parkir, perlu diadakan penebalan marka parkir di petak parkir yang ada saat ini dan pengembangaan Terminal Kargo Denpasar diharapkan dapat segera direalisasikan demi meminimalisir terjadinya aktivitas bongkar muat di badan jalan.

\section{DAFTAR PUSTAKA}

Abubakar, I. 1998. Pedoman Perencanaan dan Pengoperasian Fasilitas Parkir, Direktorat Bina Lalu Lintas dan Angkutan Kota Jenderal Perhubungan.

Anonim. 1996. Menuju Lalu Lintas dan Angkutan Jalan yang Tertib. Jakarta: Direktorat Jenderal Perhubungan Darat.

Hobbs, F.D. 1974. Perencanaan dan Teknik Lalu Lintas. (Suprapto, Waldijono, Pentj). Jakarta: Penerbit UGM.

Morlok, E.K. 1985. Pengantar dan Perencanaan Transportasi. (Johan Kelanaputra Hainim, Pentj). Jakarta: Erlangga.

Oppenlander, J.C. and Box P.C. 1976. Manual of Traffic Engineering Studies. Fourt Edition. Institute of Transportation Engineering Washington DC.

Warpani, S.P. 1990. Merencanakan Sistem Perangkutan. Bandung: ITB. 